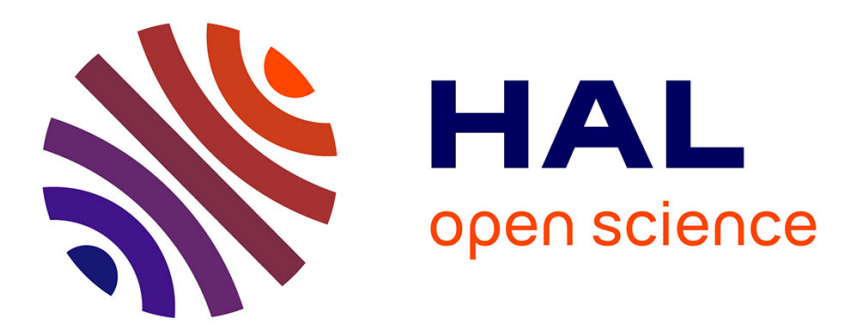

\title{
Proteomic screen for potential regulators of M-phase entry and quality of meiotic resumption in Xenopus laevis oocytes.
}

Romain d'Inca, Gaëlle Marteil, Franck Bazile, Aude Pascal, Nathalie Guitton, Régis Lavigne, Laurent Richard-Parpaillon, Jacek Kubiak

\section{To cite this version:}

Romain d'Inca, Gaëlle Marteil, Franck Bazile, Aude Pascal, Nathalie Guitton, et al.. Proteomic screen for potential regulators of M-phase entry and quality of meiotic resumption in Xenopus laevis oocytes.. Journal of Proteomics, 2010, 73 (8), pp.1542-50. 10.1016/j.jprot.2010.03.017 . inserm-00469265

\section{HAL Id: inserm-00469265 https://www.hal.inserm.fr/inserm-00469265}

Submitted on 11 May 2010

HAL is a multi-disciplinary open access archive for the deposit and dissemination of scientific research documents, whether they are published or not. The documents may come from teaching and research institutions in France or abroad, or from public or private research centers.
L'archive ouverte pluridisciplinaire HAL, est destinée au dépôt et à la diffusion de documents scientifiques de niveau recherche, publiés ou non, émanant des établissements d'enseignement et de recherche français ou étrangers, des laboratoires publics ou privés. 
Submitted to J. Proteomics on November $30^{\text {th }}, 2009$

Revised on March $16^{\text {th }}, 2010$

Accepted on March $33^{\text {st }}, 2010$

Proteomic screen for potential regulators of M-phase entry and quality of meiotic resumption in Xenopus laevis oocytes

Romain D’Inca ${ }^{1}$, Gaëlle Marteil ${ }^{1}$, Franck Bazile ${ }^{1}$, Aude Pascal ${ }^{1}$, Nathalie Guitton ${ }^{2}$, Régis Lavigne $^{2}$, Laurent Richard-Parpaillon ${ }^{1}$, Jacek Z. Kubiak ${ }^{1 *}$

${ }^{1}$ CNRS UMR 6061/University of Rennes 1, Institute of Genetics \& Development, Cell Cycle Group, IFR 140 GFAS, Faculty of Medicine, Rennes, France;

${ }^{2}$ Proteomics Core Facility Biogenouest, Inserm U625, Campus de Beaulieu, 35042 Rennes, France

* Corresponding author's e-mail : Jacek.Kubiak@univ-rennes1.fr 


\begin{abstract}
The quality of oocytes depends largely on the capacity to resume meiotic maturation. In Xenopus laevis, only fully grown oocytes react to progesterone stimulation by resumption of meiotic maturation associated with the entry into the meiotic M-phase. Proteins involved in this process are poorly known. To identify novel proteins regulating M-phase entry, we performed a differential proteomic screen. We compared proteomes of fully grown stage VI oocytes characterized as poorly or highly responsive to progesterone treatment. The comparison of 2-D gels allowed us to identify several spots including two specifically present in highly responsive oocytes and two specifically present in poorly responsive ones. By mass spectrometry we identified the two proteins specifically present in highly responsive oocytes as inosine 5'monophosphate cyclohydrolase and YjgF homologues, and the two specifically present in poorly responsive oocytes as elongation factor 2 (EF2) and S-adenosyl-Lhomocysteine hydrolase (SAHH). The proteins specifically expressed in highly responsive oocytes may participate in the stimulation of meiotic maturation and M-phase entry, while the proteins specifically present in poorly maturing oocytes may participate in the inhibition of meiotic resumption.
\end{abstract}

\title{
Keywords
}

GVBD, M-phase induction, oocyte maturation enhancer, oocyte maturation repressor, oocyte quality, oogenesis, progesterone, proteome 


\section{List of abbreviations}

GV Germinal Vesicle

GVBD Germinal Vesicle BreakDown

PKA Protein Kinase A

SAHH S-Adenosyl-L-Homocysteine Hydrolase

EF2 Elongation Factor 2 


\section{Introduction}

Oocytes of vertebrates develop their capacity to support meiotic maturation and further embryonic development during the whole period of oogenesis [1]. During their growth, oocytes continuously arrested in the first meiotic prophase accumulate in the cytoplasm numerous proteins, mRNAs, lipids and sugars. In Xenopus laevis, only fully grown oocytes (classified as stage VI [2]) become reactive to the action of progestins. Upon progesterone treatment, isolated stage VI oocytes exit from the prophase arrest and undergo meiotic resumption. This is manifested by the Germinal Vesicle (GV) Breakdown (GVBD) and is macroscopically visible due to the white spot formation at the pigmented animal pole of the oocyte. This white spot is formed by exocentric movement of cytoplasmic pigment granules due to the migration of GV to the animal pole. GVBD is then followed by further condensation of chromosomes and the meiotic spindle assembly. So, the appearance of a white spot is the first and straightforward manifestation of the oocyte quality to support meiotic maturation [1].

The oocytes quality depends entirely on maternal sources accumulated during oogenesis and especially during oocytes growth. Among them, proteins and mRNAs play the most important role. mRNAs accumulated in oocytes are used for protein synthesis not only during the whole period of oocytes growth, but also after fertilization until the mid-blastula transition (MBT) [3]. Importantly, since transcription is silenced in maturing stage VI oocytes and during early embryonic development, new mRNAs do not appear during this period. However, the proteome of growing and maturing oocytes constantly evolves. Indeed, maternal mRNAs can be modified by deadenylation or polyadenylation of their 3'UTR regions, which directly modulate their stability [4-7], as well as masking or unmasking usually correlated with respective increase and decrease of their translation (both reviewed in [8]). A large part of novel proteins accumulating in oocytes is also taken up from blood. To summarize, proteins positively involved in regulation of oocyte maturation and embryo development (inducers or enhancers of meiotic maturation) are most probably newly synthesized on the basis of preexisting mRNAs in oocytes ready to undergo meiotic maturation (stage VI). Some regulatory proteins (e.g. meiotic inhibitors or repressors) can be degraded at this stage allowing oocyte maturation to occur. Both inducers and inhibitors can be also activated or inactivated respectively e.g. via postranslational modifications, which could change their position in 2-D gels. 
A number of modern analytical methods is used to identify proteins/genes involved in the oocyte quality. Among them proteomic and micro array techniques are the most powerful [9]. Numerous proteomic studies concern oocyte maturation or activation leading to embryo development (pig: [10,11]; bovin: [12]; mouse: [13-15]; reviewed in [16]. However, no publication was reported on a proteomic analysis of oocytes with different capacities to undergo meiotic maturation. The pioneering study made in the trout concerns the identification of proteins of the coelomic fluid in which oocytes undergo aging following maturation [17].

As the meiotic resumption consists of the entry to the first meiotic M-phase, one can suppose that among the regulatory proteins some classical proteins regulating M-phase entry should be involved. Indeed, it was shown that stage VI oocytes contain polo-like kinase (one of the major enzymes involved in M-phase regulation) in contrast to small, stage IV oocytes [18]. The absence of polo-like kinase partly explains why small oocytes are unable to enter the first meiotic M-phase. However, the meiotic resumption depends also on oocyte-specific events. For instance, the capacity to exit from the oocyte prophase arrest is largely prevented by high activity of PKA $[19,20]$. Thus, oocyte incompetence to resume meiosis may also relay on the molecular machinery maintaining or inactivating PKA acting up-stream from the M-phase induction. Proteins involved in these processes are even less characterized than those directly involved in M-phase entry [21]. Recently, we have compared proteomes of competent (stage VI) and incompetent (stage IV) Xenopus laevis oocytes and found that EP45 (Estrogen regulated Protein $45 \mathrm{kDa}$ ) accumulate in growing oocytes. Moreover, we showed that EP45 has an "oocyte maturation enhancer" (Omen) activity [22]). This protein does not make part of the core machinery of the M-phase entry, but its identification as Omen demonstrates the importance of accessory proteins/processes in M-phase entry and reinitiation of oocyte maturation.

Here we study proteomes of two distinguished types of Xenopus laevis oocytes corresponding to fully grown, morphologically identical, stage VI prophase I-arrested oocytes obtained from six distinct females. Most oocytes from the same female share a similar kinetic of maturation following progesterone stimulation and thus could be classified as 1 . poorly responsive or 2 . highly responsive to progesterone. In parallel to the tests of the capacity to resume meiotic maturation, the cytoplasmic fraction from non-treated prophase I arrested oocytes from each 
pool were compared by 2D-analysis followed by MS analysis. In this way we wished to identify differences in the proteomes of the two physiologically distinguished types of oocytes potentially relative to their capacity to resume meiotic maturation and the M-phase entry.

\section{Material and methods}

\subsection{Oocytes preparation and testing for the capacity to resume maturation}

Xenopus laevis females were purchased from NASCO (Fort Atkinson, WI). Stage VI oocytes were manually isolated from ovary after digestion in calcium-free OR2 $(82.5 \mathrm{mM} \mathrm{NaCl}$, 2.5mM KCl, $1 \mathrm{mM} \mathrm{MgCl} 2,5 \mathrm{mM}$ Hepes, $\mathrm{pH} 7.4)$ containing 275 units $/ \mathrm{mL}$ of collagenase (type 1A, Sigma). Oocytes were treated with 50, 100, 300 and $1000 \mathrm{nM}$ progesterone and scored for white spot appearance at the animal pole of oocytes. The pools of oocytes were classified as poorly or highly reactive by comparison of the percentage of mature oocytes $24 \mathrm{~h}$ hours after stimulation by progesterone. Highly reactive oocytes attained at least $80 \%$ of maturation upon $1000 \mathrm{nM}$ progesterone treatment after 24 hours, while the poorly reactive ones did not exceed $40 \%$.

\subsection{Sample preparation}

Oocytes were homogenized in MPF (80mM $\beta$-glycerophosphate, $50 \mathrm{mM} \mathrm{NaF}, 20 \mathrm{mM}$ EGTA, $20 \mathrm{mM}$ Hepes, $15 \mathrm{mM} \mathrm{MgCl} 2,1 \mathrm{mM}$ DTT, pH 7.5) supplemented with Aprotinin $(10 \mu \mathrm{g} / \mathrm{mL})$, Leupeptin $(10 \mu \mathrm{g} / \mathrm{mL})$, Pepstatin $(10 \mu \mathrm{g} / \mathrm{mL})$, AEBSF $(1 \mathrm{mM})$ and Na orthovanadate $(1 \mathrm{mM})$ and centrifuged (13000 rpm, $15 \mathrm{~min}, 4^{\circ} \mathrm{C}$ ). The oocyte extract was then collected and PBS buffer was added. Lipids were finally removed by Freon extraction.

\subsection{2-D electrophoresis for MS analysis}

Protein extract (40 $\mu \mathrm{g}$ for silver stained gels and $310 \mu \mathrm{g}$ for Coomassie blue stained gels) were diluted in DeStreak buffer (GE Healthcare) to a final volume of $450 \mu$ l. First dimension isoelectric focusing was carried out on an IPGphor system (GE Healthcare) by using precast immobilized $\mathrm{pH}$ gradient strips (pH 3 to 10 linear, GE Healthcare). After rehydratation of the strips, isoelectric focusing was performed during 19 hours with a gradually increasing voltage. The strips were then allowed to equilibrate with 2 incubations for $15 \mathrm{~min}$ each at room 
temperature in a solution of $20 \mathrm{ml}$ of $50 \mathrm{mM}$ Tris-HCL pH 8.2, $6 \mathrm{M}$ urea, 30\% glycerol, 2\% SDS, containing $65 \mathrm{mM}$ DTT for the first incubation and later for 15 min with $250 \mathrm{mM}$ iodoacetamide. Strips were applied to the top of a $12.5 \%$ SDS-polyacrylamide gel and run in a vertical Ettan DALT Six System (GE Healthcare). For each pool of oocytes one gel was made. For preliminary experiments, gels were silver-stained as previously described [23]. For MS analysis, gels were stained in a solution of $0.1 \%$ Coomassie blue, fixed in a solution of $18 \%$ ethanol/9\% acetic acid and then washed in MilliQ water overnight. Following staining, gels were scanned at 300 dpi resolution with an ImageScanner ${ }^{\mathrm{TM}}$ (GE Healthcare), and an automatic spot detection algorithm of the ImageMaster ${ }^{\mathrm{TM}} 2 \mathrm{D}$ platinum 5.0 software (GE Healthcare) was used. Results were manually verified and eventually edited. Next, some constant spots among all gels were used as landmarks by the software in order to match different gels. Finally, spots differentially present between gels were automatically detected and the most prominent and evident differential spots were further analyzed by mass spectrometry.

\subsection{MS analysis and protein identification}

Spots of interest were excised from the gel by using an Ettan Spot Handling Workstation (GE Healthcare). Gel plugs were washed in MilliQ water, once in 100nm Na2S2O3 once in 50\% methanol/50 $\mathrm{mM}$ ammonium bicarbonate and once in $75 \%$ acetonitrile and dried. In gel digestion were performed by incubation for $60 \mathrm{~min}$ with $340 \mathrm{UI} / \mathrm{mL}$ sequencing grade modified porcine trypsin (Promega, Charbonnières-les-bains, France) in $20 \mathrm{mM} \mathrm{NH} 4 \mathrm{HCO} 3$. Extraction was performed in two successive steps, by adding 50\% acetonitrile and $0.1 \%$ trifluoroacetic acid. Digests were dried out and dissolved in $2 \mathrm{mg} / \mathrm{mL} \alpha$-cyano-4hydroxycinnamic acid in 70\% ACN/0.1\% TFA, before spotting onto MALDI targets (384 Scout MTP $600 \mu \mathrm{m}$ AnchorChip; Bruker Daltonik, GmbH, Bremen, Germany). Mass fingerprints were acquired using a MALDI-TOF/TOF mass spectrometer (Ultraflex MALDI Mass Spectrometers (Bruker Daltonik, $\mathrm{GmbH}$ ) and processed with FlexAnalysis software (version 2.2) and ProteinScape software (version 1.3; all from Bruker Daltonik, GmbH, Bremen, Germany). After internal calibration with trypsin autodigestion peptides, the monoisotopic masses of the tryptic peptides were used to query NCBInr sequence databases (version 20060609, 3682060 sequences) using the Mascot search algorithm (Mascot server version 2.1.04; http://www.matrixscience.com). Search conditions were as follows: initial 
rather open mass window of $70 \mathrm{ppm}$ for an internal calibration, one missed cleavage allowed, modification of cysteine by iodoacetamide, and methionine oxidation and N-terminal pyroglutamylation as variable modifications. To ascertain unambiguous identification, each was carefully checked as previously described [24].

\section{Results and discussion}

\subsection{Oocytes highly and poorly responsive to progesterone}

Progesterone induces meiotic resumption in Xenopus laevis isolated oocytes. Fully grown stage VI oocytes obtained from six females were treated with 50, 100, 300 and $1000 \mathrm{nM}$ progesterone. The pools of oocytes from different females reacted differentially to progesterone (Fig. 1). Judged by the curves showing the percentage of oocyte maturation in response to different doses of progesterone, we distinguished three highly responsive and three poorly responsive pools of oocytes. Based on these experiments, non-treated oocytes from the corresponding pools were selected for proteomic screening of proteins specifically present or absent in proteomes of each pool of oocytes.

Our results show that the responsiveness of Xenopus laevis stage VI oocytes to progesterone depends on the female and that there is a great variability between females in the studied population of laboratory animals. The quality of oocytes is largely reflected by their responsiveness to progesterone. The acquisition of high responsiveness to progesterone is normally correlated with the completion of oocyte growth. However, growth and reactivity to progesterone are clearly separable, since we show here that stage VI oocytes with identical size could have different kinetic of maturation following progesterone treatment. The capacity of the oocyte to react properly to experimentally delivered progesterone can be regulated at different levels: progesterone receptors, signalling pathway leading from receptors to effectors, effectors itself contributing to the regulation of the prophase-arrest or the machinery regulating the entry into the M-phase. Oocytes quality is multifactorial and can also be influenced by different factors such as diet, housing conditions or female-specific reactions to other environmental changes [1]. 


\subsection{2-D proteomic screen and identification of proteins potentially involved in the}

quality of meiotic resumption

Extracts of cytoplasmic proteins of prophase-arrested stage VI fully grown oocytes corresponding to each pool tested for the efficiency of meiotic resumption were analysed by 2-D gel electrophoresis followed by silver staining. In order to focus on the most evident and unambiguously differentially expressed proteins, we selected for mass spectrometry identification only spots present in an 'all or nothing" fashion between highly or poorly responsive oocytes (i.e. systematically present or absent in all three highly or poorly responsive pools of oocytes).

Two spots corresponding to protein specifically present in pools of highly responsive oocytes and absent in poorly responsive ones were found. Those spots were identified by mass spectrometry as inosine 5'monophosphate cyclohydrolase (GenBank accession number: AAH72321.1) and YjgF homologue (GenBank accession number: AAH68875) (Fig. 2, 3, 4). Analogically, also two spots present exclusively in pools of poorly responsive oocyte were found. They correspond to elongation factor 2 (EF2) (GenBank accession number: AAH44327) and S-adenosyl-L-homocysteine hydrolase (SAHH, Genbank accession number: AAH73400) (Fig. 2, 3, 4).

The inosine 5'monophosphate cyclohydrolase is involved in catalysis of the synthesis of purines. This de novo synthesis of purines is a critical step in cell cycle progression and could be regulated by various growth factors via the PI3K/Akt pathway [25]. It was also reported to participate in hypoxantine transport in Neurospora crassa [26]. YjgF belongs to a highly conserved YjgF/Yer057p/UK114 family of proteins across prokaryotes and eukaryotes with no precise function attributed so far. YjgF was identified in a proteomic screen of small proteins in E. coli (27). Interestingly enough, it has been shown that a member of this family is also involved in purine metabolism in Bacillus subtilis [28]. Our finding which shows that two different proteins potentially involved in the synthesis of purine are specifically present in highly responsive oocytes is very promising. Indeed, previous works in mouse cumulus cellenclosed oocytes have also shown a link between oocyte maturation and requirement of purine synthesis [29, 30]. Otherwise, this requirement of purine synthesis has never been shown in frog oocytes. Further analysis using specific inhibitor of purine metabolism will be required to validate this hypothesis in our model. 
For the proteins found specifically expressed in poorly responsive oocyte, an involvement in oocyte maturation seems less obvious. EF2 is involved in regulation of the elongation phase of translation. Its activity was shown to be down regulated in stage VI Xenopus leavis oocytes most probably via changes in its phosphorylation [31]; reviewed in [32]. It is therefore likely that the EF2 isoform found in our screen as a spot missing in highly responsive oocytes represent a specifically phosphoryated form of EF2. Further investigation should enable to verify this hypothesis.

Interestingly, SAHH was shown to be directly involved in cell cycle regulation [33, 34], proliferation and tumorigenesis and is over expressed in numerous colon and kidney cancers [35]. It is a highly conserved, ubiquitous enzyme and the only one known in vertebrates to hydrolyse S-adenosylhomocysteine $(\mathrm{SAH})$, which is a by product of $\mathrm{S}$ adenosylmethionine(SAM)-dependent methylations [33]. SAHH hydrolase activity positively regulates biomethylation of DNA, RNA, lipids and proteins by decreasing the intracellular level of SAH [33, 34]. Probably for the same reason it is also a potent regulator of transcription and was shown to associate both with mRNA(guanine-7-) methyltransferase and RNA polymerase II transcriptosome [36]. Similarly to the pair of spots specifically present in highly-responsive oocytes (inosine 5'monophosphate cyclohydrolase and YjgF) and potentially involved in purine metabolism, both SAHH and EF2 were found in a proteomic screen made in rat astrocytes in response to oxidative stress induced by $\mathrm{H}_{2} \mathrm{O}_{2}$ to be increased (37). This may suggest that the presence of the two specific spots corresponding to these proteins in poorly maturing oocytes could reflect a response of these oocytes to a stress similar to the oxidative stress. The gene coding for SAHH protein in the mouse is essential during embryonic development since mouse embryos with SAHH-coding gene knock out die early during embryogenesis [38]. During Xenoups laevis oogenesis, SAHH protein is already present in oogonia, and accumulates during oocyte growth of prophase-arrested oocytes transcribing maternal mRNAs [39]. In prophase oocytes, it remains both cytoplasmic and nuclear with the intranuclear concentration estimated as 11-fold of the cytoplasmic [23, 28]. In prophase-arrested oocytes, SAHH seems not to be phosphorylated and its phosphorylation was noticed only during oocyte maturation [40]. This posttranslational modification could lead to changes of electrophoretic mobility of SAAH in 2-D gels. Thus, one hypothesis would be that only highly responsive oocytes may contain this modified isoform(s). 
We have recently shown that Xenopus laevis oocytes develop Omen (Oocyte maturation enhancer) activity and hypothesized that Omre (Oocyte maturation repressor) activity could exist [22]. SAHH and EF2 forms found in the current study may fulfill the last criterion, while inosine 5'monophosphate cyclohydrolase and YjgF may play the role as Omen factors. Further functional analysis of proteins identified in this screen is required in order to pinpoint their involvement in M-phase entry and oocyte maturation. Our data obtained in this screen already indicates that proteomic analysis could be a very attractive tool to identify new markers of oocyte quality.

\section{Acknowledgements}

This work was supported by grants from ARC (4900) and Ligue Contre le Cancer (Comité d'Ille-et-Vilaine et de Vendée) to J.Z.K. Proteomics analyses were supported by the Proteomics Core Facility Biogenouest. The authors would like to thank Dr C. Pineau for valuable discussions and help during the mass spectrometry experiments.

\section{References}

[1] Marteil G, Richard-Parpaillon L, Kubiak JZ. Role of oocyte quality in meiotic maturation and embryonic development. Reprod. Biol. 2009;9:203-24.

[2] Dumont JN. Oogenesis in Xenopus laevis (Daudin). I. Stages of oocyte development in laboratory maintained animals. Journal of Morphology 1972;136:153-79.

[3] Newport J, Kirschner M. A major developmental transition in early Xenopus embryos: II. Control of the onset of transcription. Cell 1982;30:687-96.

[4] Paris J, Osborne HB, Couturier A, Le Guellec R, Philippe M. Changes in the polyadenylation of specific stable RNA during the early development of Xenopus laevis. Gene 1988;72:169-76.

[5] Audic Y, Omilli F, Osborne HB. Postfertilization deadenylation of mRNAs in Xenopus laevis embryos is sufficient to cause their degradation at the blastula stage. Mol Cell Biol. 1997;17:209-18. 
[6] Paillard L, Omilli F, Legagneux V, Bassez T, Maniey D, Osborne HB. EDEN and EDEN$\mathrm{BP}$, a cis element and an associated factor that mediate sequence-specific mRNA deadenylation in Xenopus embryos. EMBO J. 1998;17:278-87.

[7] Detivaud L, Pascreau G, Karaiskou A, Osborne HB, Kubiak JZ. Regulation of EDENdependent deadenylation of Aurora A/Eg2-derived mRNA via phosphorylation and dephosphorylation in Xenopus laevis egg extracts. J Cell Sci. 2003;116;2697-705.

[8] Radford HE, Meijer HA, de Moor CH. Translational control by cytoplasmic polyadenylation in Xenopus oocytes. Biochim Biophys Acta. 2008;1779:217-29.

[9] Patrizio P, Fragouli E, Bianchi V, Borini A, Wells D. Molecular methods for selection of the ideal oocyte. Reprod Biomed Online. 2007;15:346-53.

[10] Ellederova Z, Halada P, Man P, Kubelka M, Motlik J, Kovarova H. Protein patterns of pig oocytes during in vitro maturation. Biol Reprod. 2004;71:1533-9.

[11] Gupta MK, Jang JM, Jung JW, Uhm SJ, Kim KP, Lee HT. Proteomic analysis of parthenogenetic and in vitro fertilized porcine embryos. Proteomics 2009;9:2846-60.

[12] Memili E, Peddinti D, Shack LA, Nanduri B, McCarthy F, Sagirkaya H, Burgess SC. Bovine germinal vesicle oocyte and cumulus cell proteomics. Reproduction 2007; 133:1107-20.

[13] Vitale AM, Calvert ME, Mallavarapu M, Yurttas P, Perlin J, Herr J, Coonrod S. Proteomic profiling of murine oocyte maturation. Mol Reprod Dev. 2007;74:608-16.

[14] Ma M, Guo X, Wang F, Zhao C, Liu Z, Shi Z, Wang Y, Zhang P, Zhang K, Wang N, Lin M, Zhou Z, Liu J, Li Q, Wang L, Huo R, Sha J, Zhou Q. Protein expression profile of the mouse metaphase-II oocyte. J Proteome Res. 2008;7:4821-30.

[15] Zhang P, Ni X, Guo Y, Guo X, Wang Y, Zhou Z, Huo R, Sha J. Proteomic-based identification of maternal proteins in mature mouse oocytes. BMC Genomics 2009; $10: 348$. 
[16] Yurttas P, Morency E, Coonrod S. Use of proteomics to identify highly abundant maternal factors that drive the egg to embryo transition. Reproduction 2010 (in press).

[17] Rime H, Guitton N, Pineau C, Bonnet E, Bobe J, Jalabert B. Post-ovulatory ageing and egg quality: a proteomic analysis of rainbow trout coelomic fluid. Reprod Biol Endocrinol. 2004;2:26.

[18] Karaiskou A, Leprêtre AC, Pahlavan G, Du Pasquier D, Ozon R, Jessus C. Polo-like kinase confers MPF autoamplification competence to growing Xenopus oocytes. Development 2004;131:1543-52.

[19] Sadler SE, Maller JL. Progesterone inhibits adenylate cyclase in Xenopus oocytes. Action on the guanine nucleotide regulatory protein. J Biol Chem. 1981;256:6368-73.

[20] Sadler SE, Maller JL. The development of competence for meiotic maturation during oogenesis in Xenopus laevis. Dev Biol. 1984;98:165-72.

[21] Jessus C, Ozon R. How does Xenopus oocyte acquire its competence to undergo meiotic maturation? Biol Cell 2004;96:187-92.

[22] Marteil G, D’Inca R, Pascal a, Guitton N, Midtun T, Goksoyr A, Richard-Parpaillon L, Kubiak JZ. EP45 accumulates in growing Xenopus laevis oocytes and has oocyte maturation enhancing activity. J. Cell Sci. (in press).

[23] Shevchenko A, Wilm M, Vorm O, Mann M. Mass spectrometric sequencing of proteins silver-stained polyacrylamide gels. Anal. Chem. 1996;68:850-858.

[24] Com E, Evrard B, Roepstorff P, Aubry F, Pineau C. New Insights into the Rat Spermatogonial Proteome: identification of 156 additional proteins. Mol. Cell. Proteomics 2003;2:248-261.

[25] Wang W, Fridman A, Blackledge W, Connelly S, Wilson IA, Pilz RB, Boss GR. The phosphatidylinositol 3-kinase/akt cassette regulates purine nucleotide synthesis. Biol Chem. 2009;284:3521-8. 
[26] Sabina RL, Magill JM, Magill CW. Regulation of hypoxanthine transport in Neurospora crassa. J Bacteriol. 1976;128:598-603.

[27] Wasinger VC, Humphery-Smith I. Small genes/gene-products in Escherichia coli K-12. FEMS Microbiol Lett. 1998;169:375-82.

[28] Rappu P, Shin BS, Zalkin H, Mäntsälä P. A role for a highly conserved protein of unknown function in regulation of Bacillus subtilis purA by the purine repressor. $\mathbf{J}$ Bacteriol. 1999;181:3810-5.

[29] Downs SM. Involvement of purine nucleotide synthetic pathways in gonadotropininduced meiotic maturation in mouse cumulus cell-enclosed oocytes. Mol Reprod Dev. $1997 ; 46: 155-67$

[30] Downs SM. Adenosine blocks hormone-induced meiotic maturation by suppressing purine de novo synthesis. Mol Reprod Dev. 2000;56:172-9.

[31] Severinov KV, Melnikova EG, Ryazanov AG. Downregulation of the translation elongation factor 2 kinase in Xenopus laevis oocytes at the final stages of oogenesis. New Biol. 1990;2:887-93.

[32] Ryazanov AG, Rudkin BB, Spirin AS. Regulation of protein synthesis at the elongation stage. New insights into the control of gene expression in eukaryotes. FEBS Lett. $1991 ; 285: 170-5$

[33] Ueland PM. Pharmacological and biochemical aspects of S-adenosylhomocysteine and S-adenosylhomocysteine hydrolase. Pharmacol. Rev. 1982;34;223-53.

[34] Radomski N, Kaufmann C, Dreyer C. Nuclear accumulation of S-adenosylhomocysteine hydrolase in transcriptionally active cells during development of Xenopus laevis. Mol Biol Cell. 1999;10:4283-98. 
[35] Leal JF, Ferrer I, Blanco-Aparicio C, Hernández-Losa J, Ramón Y Cajal S, Carnero A, Lleonart ME. S-adenosylhomocysteine hydrolase downregulation contributes to tumorigenesis. Carcinogenesis 2008;29;2089-95.

[36] Radomski N, Barreto G, Kaufmann C, Yokoska J, Mizumoto K, Dreyer C. Interaction of S-adenosylhomocysteine hydrolase of Xenopus laevis with mRNA(guanine-7) methyltransferase: implication on its nuclear compartmentalisation and on cap methylation of hnRNA. Biochim Biophys Acta. 2002;1590:93-102.

[37] Miura Y, Kano M, Abe K, Urano S, Suzuki S, Toda T. Age-dependent variations of cell response to oxidative stress: proteomic approach to protein expression and phosphorylation. Electrophoresis. 2005;26:2786-96.

[38] Miller MW, Duhl DM, Winkes BM, Arredondo-Vega F, Saxon PJ, Wolff GL, Epstein CJ, Hershfield MS, Barsh GS. The mouse lethal nonagouti $(\mathrm{a}(\mathrm{x}))$ mutation deletes the Sadenosylhomocysteine hydrolase (Ahcy) gene. EMBO J. 1994;13:1806-16.

[39] Wedlich D, Dreyer C. Cell specificity of nuclear protein antigens in the development of Xenopus species. Cell Tissue Res. 1988;252:479-89.

[40] Dreyer C. Differential accumulation of oocyte nuclear proteins by embryonic nuclei of Xenopus. Development 1987;101:829-46.

\section{Figures legends}

Figure 1. Oocytes' response to progesterone treatment. Left : three pools of highly responsive oocytes. Right : three pools of poorly responsive oocytes. Isolated oocytes obtained from six individual females were treated with 50,100, 500 and $1000 \mathrm{nM}$ progesterone (pg) as well as with ethanol in concentration equivalent to the one present in the medium containing 1000 $\mathrm{nM}$ progesterone and scored for the white spot appearance. The third pool of poorly responsive oocytes (right, bottom) was treated only with two doses of pg: 50 and $1000 \mathrm{nM}$. 
Highly responsive oocytes attain at least $80 \%$ of maturation with $1000 \mathrm{nM}$ pg at 24 hours, while poorly responsive do not exceed $40 \%$ at 24 hours (red curve).

Figure 2. Positions on 2-D gel of differentially expressed spots identified in the screen. 1: inosine 5'monophosphate cyclohydrolase (GenBank accession number: AAH72321.1); 2 : YjgF homologue (GenBank accession number: AAH68875), 3 : elongation factor 2 (EF2) (GenBank accession number: AAH44327), 4 : S-adenosyl-L-homocysteine hydrolase (SAHH) Genbank accession number: AAH73400).

Figure 3. Representative images of differentially expressed spots identified in this screen. Spots corresponding to inosine 5'monophosphate cyclohydrolase and YjgF are absent in poorly responsive oocytes (red circles), while elongation factor 2 (EF2) and S-adenosyl-Lhomocysteine hydrolase (SAHH) are absent in highly responsive oocytes (green circles).

Figure 4 A, B, C, D . MS/MS spectra that identified spots 1, 2, 3 and 4 as inosine 5'monophosphate cyclohydrolase, YjgF, elongation factor 2 and S-adenosyl-L-homocysteine hydrolase respectively.
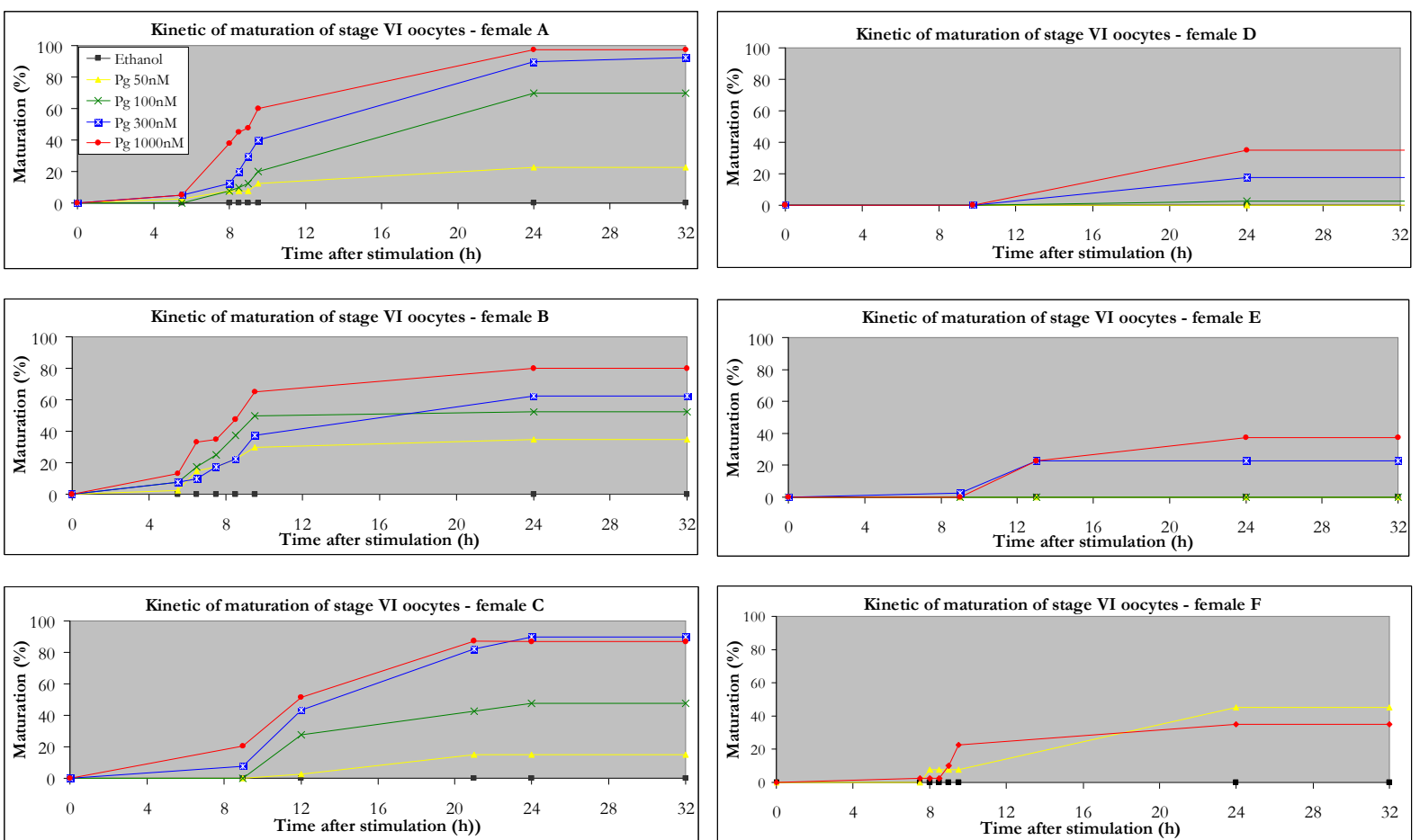

\section{Figure 1.}




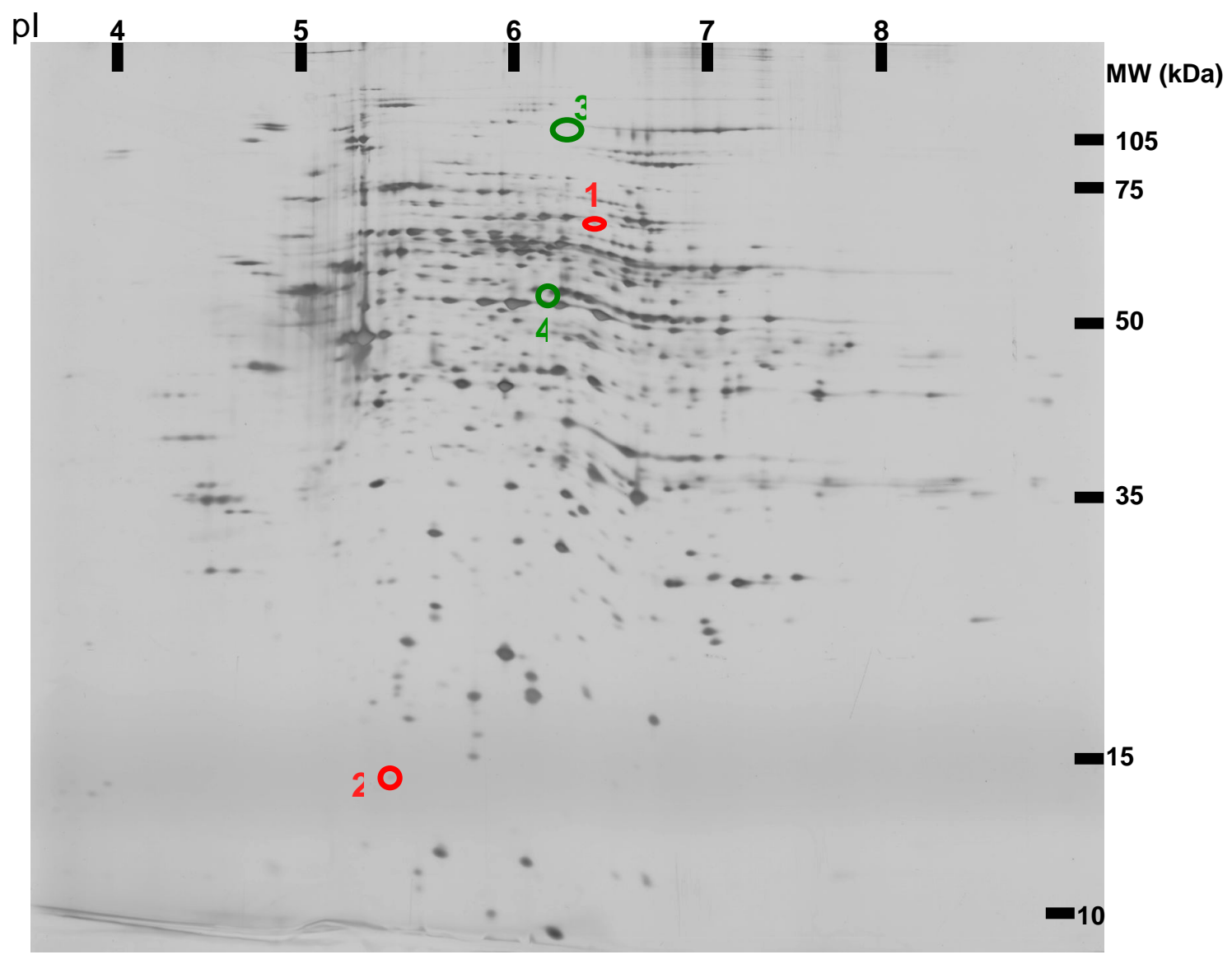

Figure 2 

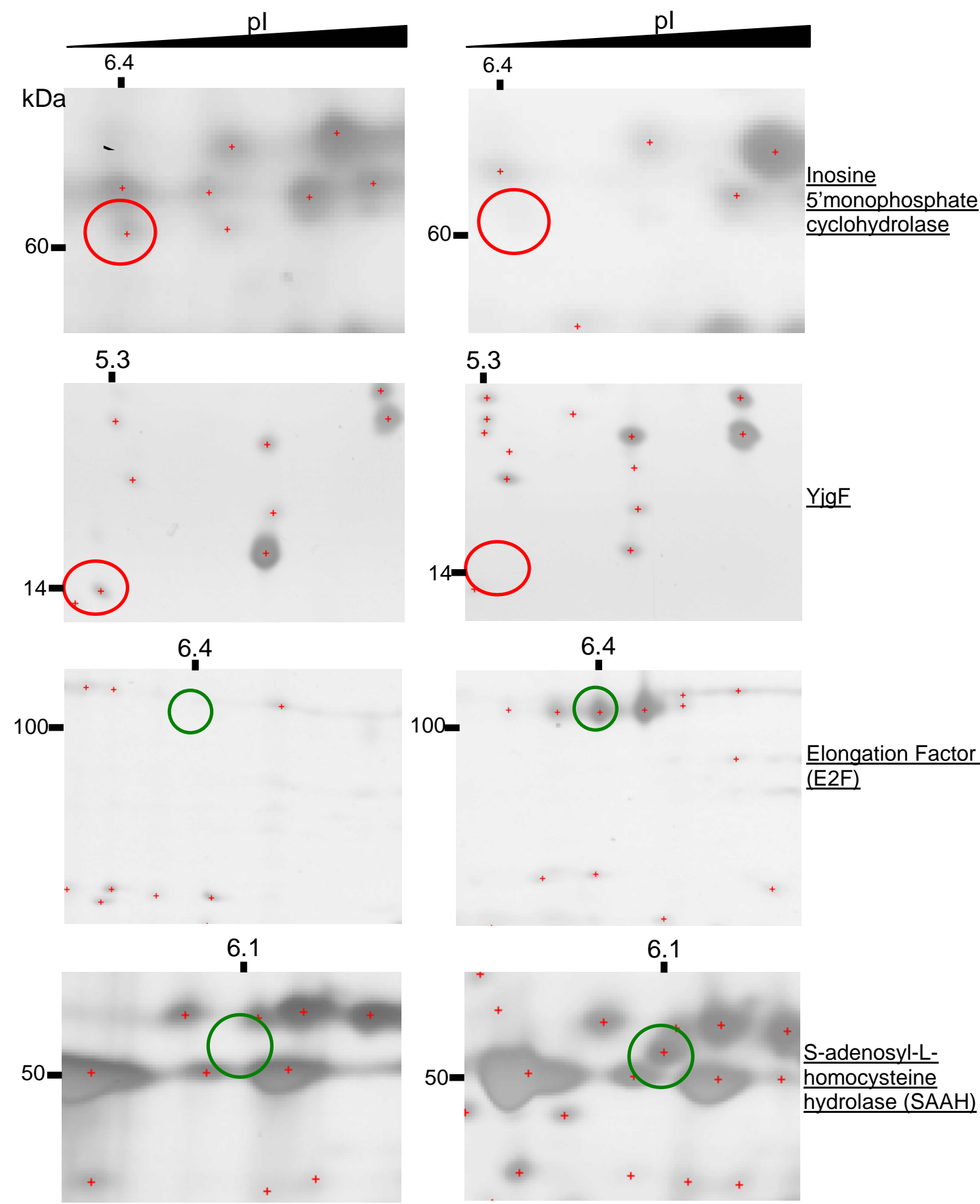

Highly

100

Elongation Factor 2 (E2F)

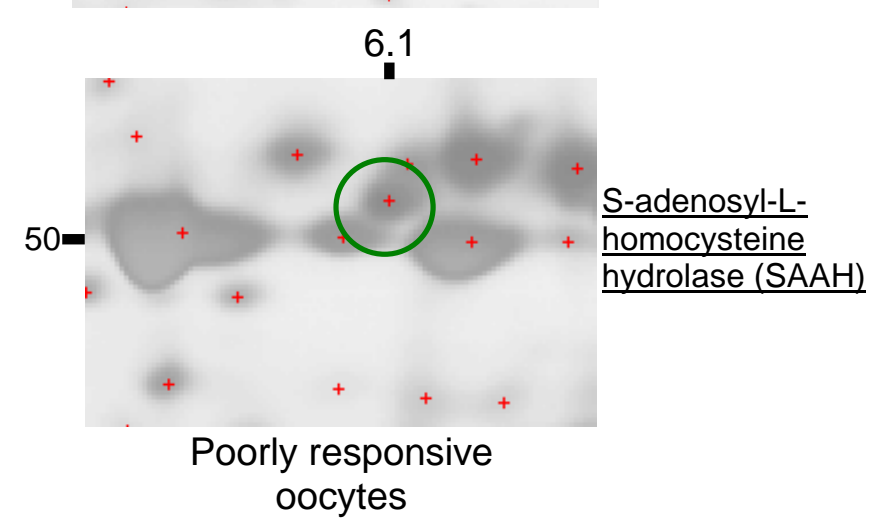

Figure 3 


\section{Spot 1: Inosine 5'monophosphate cyclohydrolase}

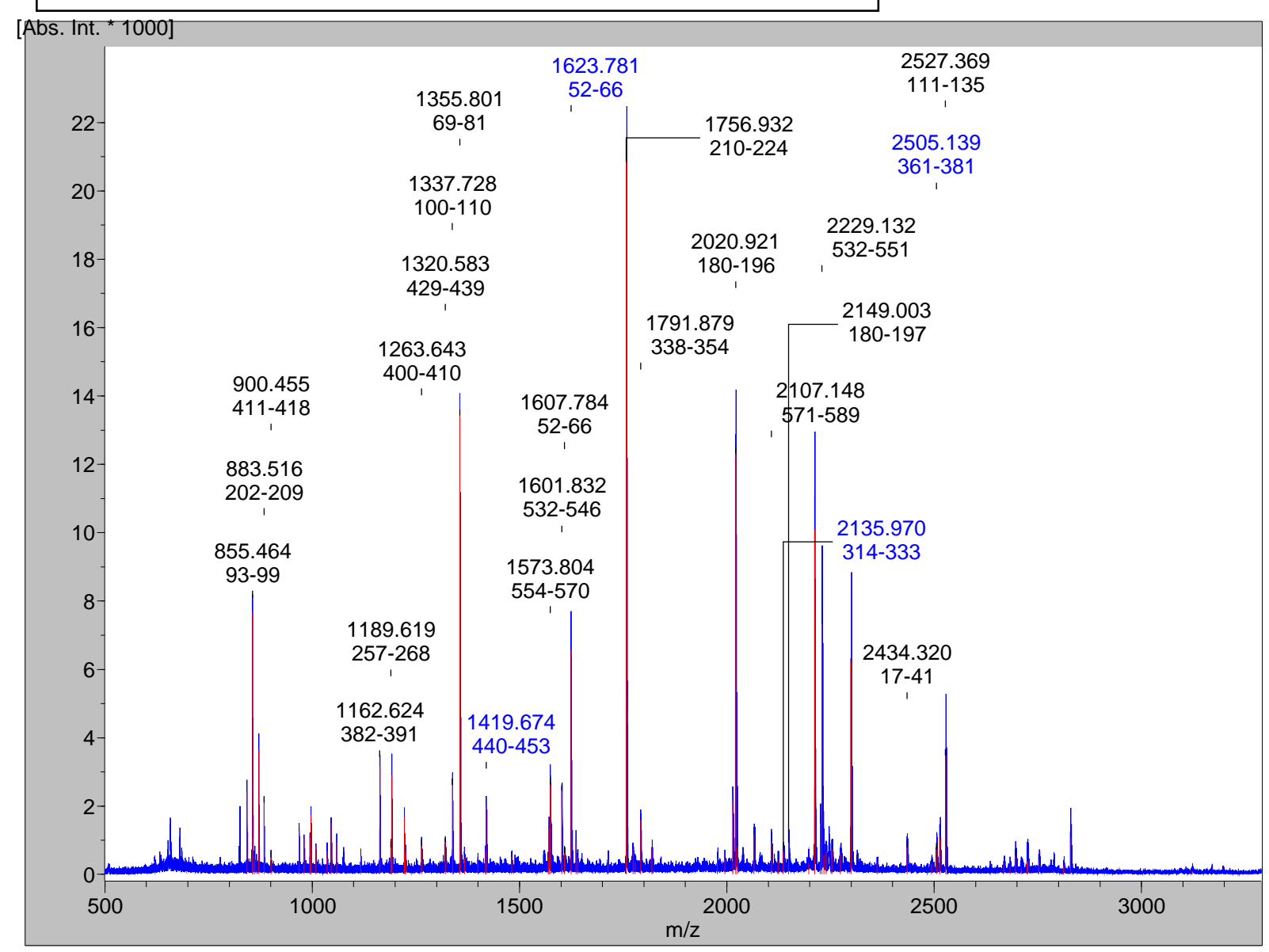

Figure 4 A 


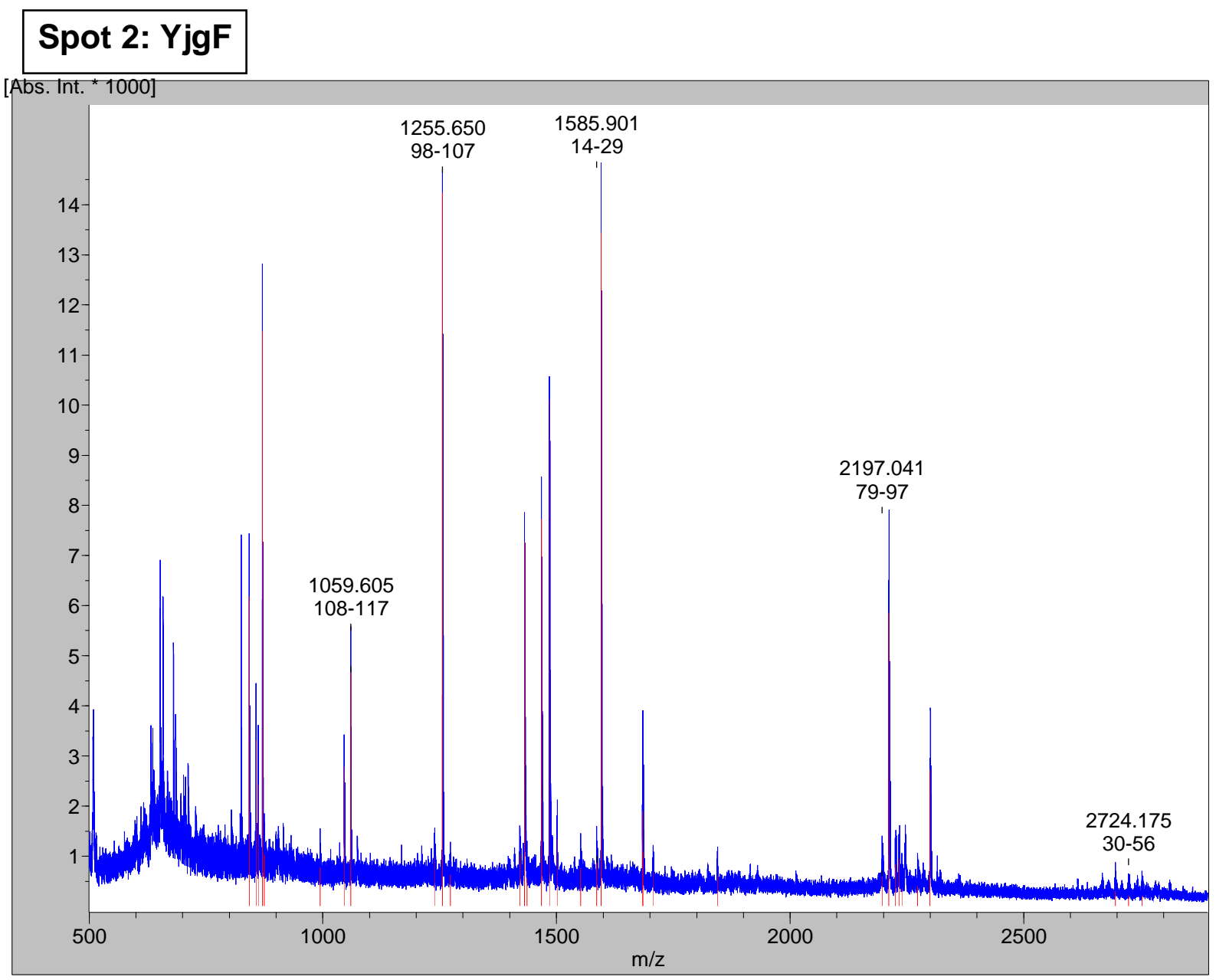

Figure 4 B 


\section{Spot 3 : Elongation factor 2 (EF2)}

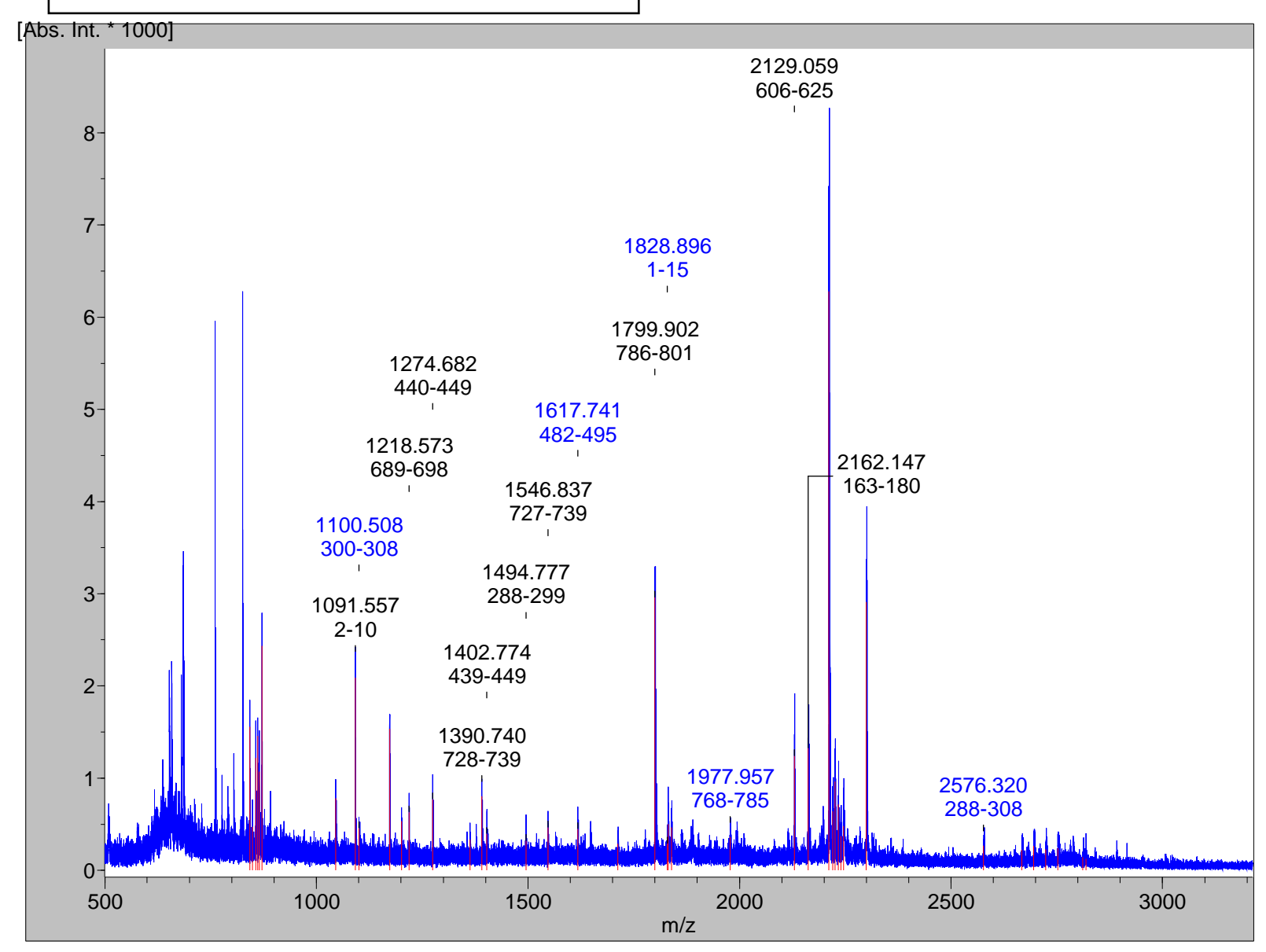

\section{Figure 4C}




\section{Spot 4 : S-adenosyl-L-homocysteine hydrolase (SAHH)}

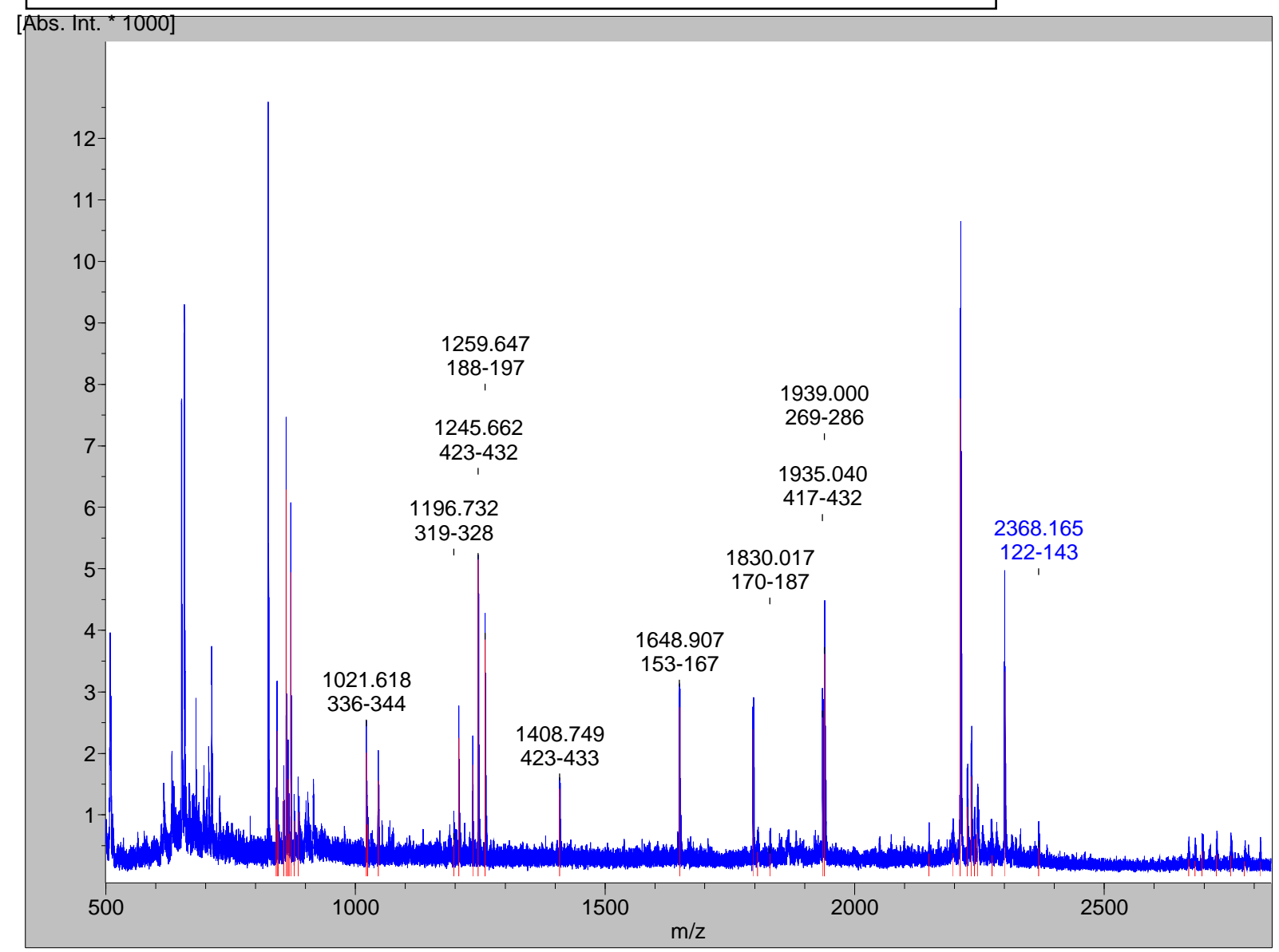

Figure 4D 